\title{
How does precipitation pH affect structural transformations during activation of Co-Mo catalyst? In situ XPRD study
}

\author{
A. Albrecht, P. Adamski, M. Nadziejko, D. Moszyński \\ West Pomeranian University of Technology in Szczecin, Faculty of Chemical Technology and Engineering, Department of Chemical \\ and Environment Engineering, Pułaskiego 10, 70-322 Szczecin, Poland \\ aleksander.albrecht@zut.edu.pl
}

Nitrides of transition metals are mostly associated with hardness and mechanical strength and tend to be thermally and electrically conductive. They exhibit the properties of both metals and ceramics [1]. On the other hand, they were proven to have high catalytic activity in various chemical reactions, e.g. ammonia synthesis, ammonia decomposition, hydrodesuplhurisation and NO reduction [2].

Particularly effective ammonia synthesis catalysts are nitrides of cobalt and molybdenum. These nitrides are usually obtained during the ammonolysis process of oxide precursors. Previous studies on cobalt molybdate reduction in ammonia confirmed the presence of multiple crystalline phases in the system, mainly: $\mathrm{CoMoO}_{4} \cdot \mathrm{nH}_{2} \mathrm{O}, \mathrm{NH}_{4} \mathrm{H}_{3} \mathrm{Co}_{2} \mathrm{Mo}_{2} \mathrm{O}_{10}, \mathrm{Co}_{2} \mathrm{Mo}_{3} \mathrm{O}_{8}, \mathrm{CoMoO}_{4}, \mathrm{Co} \mathrm{Mo}_{2} \mathrm{~N}, \mathrm{Co}_{3} \mathrm{Mo}$, $\mathrm{Co}_{3} \mathrm{Mo}_{3} \mathrm{~N}$ and $\mathrm{Co}_{2} \mathrm{Mo}_{3} \mathrm{~N}$. $\mathrm{Co}_{2} \mathrm{Mo}_{3} \mathrm{~N}$ phase is especially desirable due to its high activity in ammonia synthesis [3].

The crystalline structure of cobalt-molybdenum precursors can be modified by a change of $\mathrm{pH}$ value during their precipitation. Commonly the precipitation from the solution of cobalt(II) nitrate and ammonium heptamolybdate is conducted at pH between 5 and 6. Alkalisation of the reaction results in a different structure of the material obtained. Also, the course of the phase transformations observed for these materials by XRD analysis differs.

In the presented study, materials obtained in $\mathrm{pH} 5.5$ and 7.5 are compared. The phase transformations during calcination and ammonolysis processes were studied in the reaction chamber attached to an X-ray diffractometer (Anton Paar XRK900, Philips X'Pert Pro MPD).

At first, two different precursor phases, $\mathrm{CoMoO}_{4} \cdot \mathrm{nH}_{2} \mathrm{O}$ and $\mathrm{NH}_{4} \mathrm{H}_{3} \mathrm{Co}_{2} \mathrm{Mo}_{2} \mathrm{O}_{10}$, were obtained for $\mathrm{pH} 5.5$ and pH 7.5, respectively. After 2 hours of calcination at $300^{\circ} \mathrm{C}$ under an inert atmosphere, both precursors transformed into the $\mathrm{CoMoO}_{4}$ phase. At $500^{\circ} \mathrm{C}$, besides the dominant $\mathrm{CoMoO}_{4}$ phase, for precursor obtained in $\mathrm{pH} 7.5, \mathrm{Co}_{2} \mathrm{Mo}_{3} \mathrm{O}_{8}$ phase occurred. At $700^{\circ} \mathrm{C}$, the $\mathrm{CoMoO}_{4}$ phase gradually transforms into $\mathrm{Co}_{2} \mathrm{Mo}_{3} \mathrm{O}_{8}, \mathrm{Co}_{3} \mathrm{Mo}$ and metallic cobalt. After the ammonolysis, the concentration of main phases, $\mathrm{Co}_{3} \mathrm{Mo}_{3} \mathrm{~N}$ and $\mathrm{Co}_{2} \mathrm{Mo}_{3} \mathrm{~N}$, for both samples was similar, but the width of the diffraction peaks and the content of trace phases were significantly different.

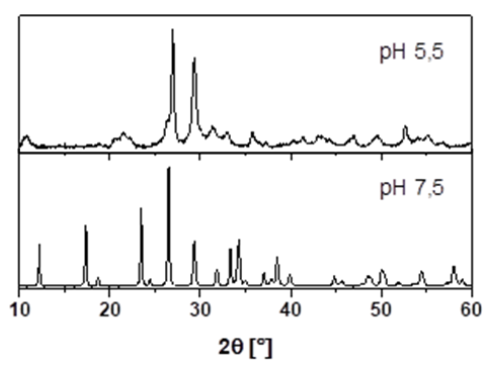

Figure 1. Ambient-condition diffractograms of the precursors obtained under $\mathrm{pH} 5.5$ and 7.5.

[1] Oyama, S. T. (1996). The Chemistry of Transition Metal Carbides and Nitrides. Blackie Academic and Professional: Glasgow.

[2] Gurram, V.R.B., Enumula, S.S., Chada, R.R., Koppadi, K.S., Burru, D. R. \& Kamaraju, S.R.R. (2018). Catal. Surv. from Asia, $22,166$.

[3] Adamski, P., Moszyński, D., Komorowska, A., Nadziejko, M., Sarnecki, A. \& Albrecht, A. (2018). Inorg. Chem. 57, 9844.

\section{Keywords: In-situ; XRPD; catalyst; cobalt molybdenum nitrides, pH}

Financed as a part of PROM Programme "International Scholarship Exchange of PhD Candidates and Academic Staff" co-financed by Polish National Agency For Academic Exchange and European Union through European Social Fund within the frame of Knowledge, Education, Development Operational Programme, project no. PPI/PRO/2019/1/00008/U/00001.

Acta Cryst. (2021), A77, C1043 